\title{
Harlequin sign concomitant with Horner syndrome after anterior cervical discectomy: a case of intrusion into the cervical sympathetic system
}

\author{
Yannick Fringeli, MD, ${ }^{1}$ Andrea M. Humm, MD, ${ }^{2}$ Alexandre Ansorge, MD, ${ }^{1}$ and \\ Gianluca Maestretti, MD1
}

\begin{abstract}
'Spine Unit, Department of Orthopaedic Surgery; and 2Unit of Neurology, Department of Internal Medicine, Cantonal Hospital
\end{abstract} Fribourg, Switzerland

\begin{abstract}
Harlequin syndrome is a rare autonomic disorder referring to the sudden development of flushing and sweating limited to one side of the face. Like Horner syndrome, associating miosis, ptosis, and anhidrosis, Harlequin syndrome is caused by disruption of the cervical sympathetic pathways. Authors of this report describe the case of a 55-year-old female who presented with both Harlequin sign and Horner syndrome immediately after anterior cervical discectomy (C6-7) with cage fusion and anterior spondylodesis. They discuss the pathophysiology underlying this striking phenomenon and the benign course of this condition. Familiarity with this unusual complication should be of particular interest for every specialist involved in cervical and thoracic surgery.
\end{abstract}

https://thejns.org/doi/abs/10.3171/2016.11.SPINE16711

KEY WORDS hemifacial flushing; facial anhidrosis; sympathetic pathways; cervical spine surgery

$\mathrm{T}$ HE anterior approach introduced by Cauchoix and Binet $^{3}$ and Southwick and Robinson ${ }^{11}$ in 1957 is the gold standard for surgical access to the lower cervical spine. In addition to causing vascular and esophageal lesions, this approach can result in iatrogenic peripheral nerve injuries. The nervous structures at particular risk are the inferior (recurrent) laryngeal nerve and the sympathetic trunk. Damage to the latter can lead to the development of Horner syndrome, which includes the classic triad of miosis, ptosis, and anhidrosis, with or without apparent enophthalmos.

Harlequin syndrome is another disorder of the sympathetic nervous system and refers to unilateral facial flushing and sweating. In 1988 Lance et al. first described this uncommon condition, ${ }^{7}$ which is caused by dysfunction in the vasomotor and sudomotor sympathetic innervation of the face. The symptoms appear contralateral to the injured side and are strictly limited to one half of the face. The disorder's name refers to a masked character of Commedia dell'arte, Italian improvisational theater of the 16th century.
Concurrent Harlequin sign and Horner syndrome are extremely rare. We report a case in which both conditions occur as a complication of cervical spinal surgery and discuss the pathophysiology underlying this striking phenomenon.

\section{Case Report}

History and Examination

A 55-year-old female presented with right C-7 radiculopathy due to a large median and right paramedian disc hernia between the C-6 and C-7 vertebrae. No sensorimotor deficits or gait or genito-sphincter dysfunctions were reported. Medical conditions included morbid obesity (WHO Class 2, body mass index $37.8 \mathrm{~kg} / \mathrm{m}^{2}$ ), hypertension, hypercholesterolemia, and obstructive sleep apnea syndrome. She had never previously undergone any cervical operation. Neurological examination revealed no focal deficits and did not show any signs of cervical myelopathy. Because there was no pain relief despite long-term analgesia, we opted for surgical treatment. 


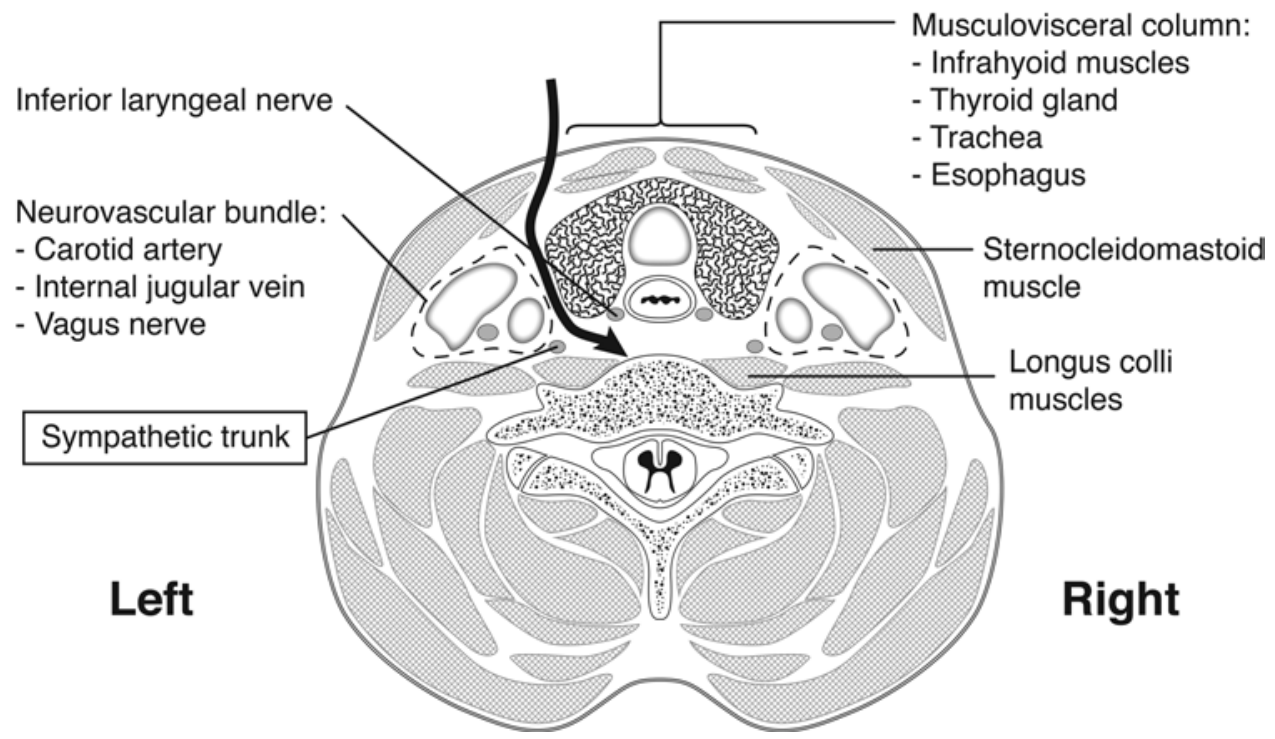

FIG. 1. Cross-sectional anatomy at the level of C-6. Arrow indicates the anterior cervical approach. Copyright Jérôme Kaufmann. Published with permission.

\section{Operation}

Using a left-sided anterior approach, we performed a C6-7 discectomy with cage fusion using the Scarlet system (Spineart). The approach along with relevant anatomical structures is presented in Fig. 1. To improve stability, we performed an additional anterior interbody spondylodesis (C6-7) using the cervical spine locking plate (CSLP) from DePuy Synthes (Johnson \& Johnson AG). At the end of surgery, a drain was inserted. The operation was performed with the patient under general anesthesia without any complications.

\section{Postoperative Course}

Immediately after surgery, the patient developed significant right-sided facial flushing with sweating. The redness was well demarcated at the midline and was associated with left-sided facial anhidrosis, miosis, and ptosis. No oculomotor, sensory, or motor facial abnormalities were noted. Sensory and motor examination of the trunk and limbs was also normal.

Cerebral and cervical CT angiography was urgently performed and ruled out any ischemic and hemorrhagic complications, hematoma, or a compressive process at the surgical site. The position of the implanted material was also correct, and the great cervical vessels showed good flow and permeability. The only relevant finding was the position of the drain, which was very close to the posterior wall of the left common carotid artery and the sympathetic trunk (Fig. 2). Therefore, we suspected a probable irritating and/or compressive effect due to the drain, which was instantly removed.

Hemifacial flushing, sweating, and anhidrosis disappeared entirely after only a few hours, and the Horner syndrome resolved almost completely. Further recovery was uneventful, and the patient was discharged after 3 days. At the 10-month follow-up, the patient was pain free. The Horner syndrome had completely disappeared, and no recurrence of the hemifacial flushing had occurred even in the case of physical activity, heat exposure, and/or emotional stress.

\section{Discussion}

Harlequin syndrome refers to the appearance of flushing and sweating limited to one side of the face. It results from dysfunction of the sympathetic vasodilator and sudomotor fibers of the face on the ipsilateral side of the affected sympathetic pathways. The underlying pathophysiological mechanism involves compensatory thermoregulatory vasodilation with flushing of the contralateral, uninjured side. ${ }^{9,15}$ Because sudomotor neurons follow the same pathways as the vasodilator neurons, hemifacial anhidrosis occurs on the affected side with contralateral compensatory sweating. The phrase "Harlequin syndrome" refers to patients presenting with hemifacial flushing and sweating in the absence of other neurological symptoms, whereas
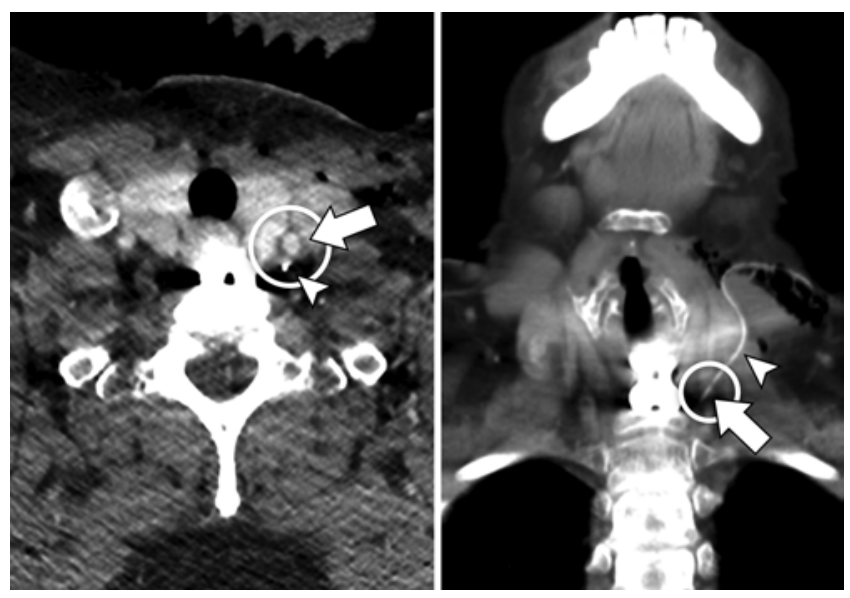

FIG. 2. Axial (left) and frontal (right) cervical CT angiograms showing the location of the drain (arrowhead) on the posterior wall of the left common carotid artery (arrow), close to the assumed position of the sympathetic trunk. 


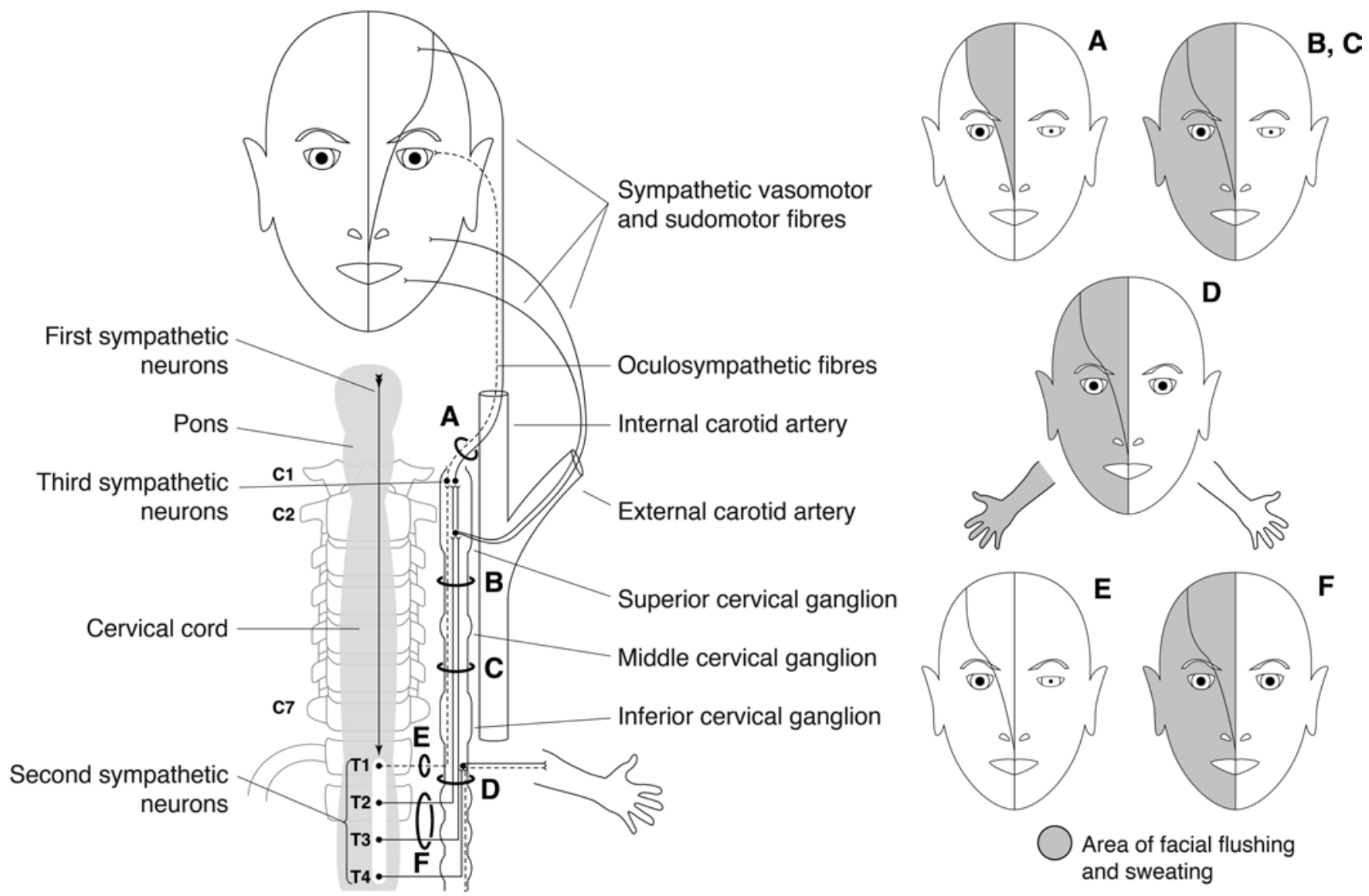

FIG. 3. Schematic of the cervical sympathetic pathways (left) and pattern of symptoms according to the lesion site (right). A lesion around the internal carotid artery is likely to disrupt the oculosympathetic supply and cause Horner syndrome with inconstant flushing of the medial aspect of the contralateral forehead and nose $(\mathbf{A})$. Lesions between the stellate ganglion and the superior cervical ganglion could give rise to concurrent Harlequin sign and Horner syndrome (B, C). A lesion below T-1 could cause Harlequin syndrome with (D) or without $(F)$ involvement of the upper extremity and the trunk but is unlikely to produce Horner syndrome. A lesion of the first ventral thoracic root will solely cause Horner syndrome (E). Of note, this pattern of symptoms is theoretical and also subject to individual anatomical variations. Copyright Jérôme Kaufmann. Published with permission.

"Harlequin sign" is used to describe flushing and sweating associated with other autonomic signs or syndromes, ${ }^{15,16}$ such as Horner syndrome in our case.

In a literature review of 108 cases of Harlequin syndrome, Guilloton et al. found 59 idiopathic cases (54.6\%) and 49 cases with a secondary or iatrogenic origin (45.4\%). ${ }^{6}$ They listed 48 cases of pure Harlequin syndrome (44.4\%) and 60 cases of Harlequin sign (55.6\%) associated with other autonomic disorders such as Horner syndrome, Holmes-Adie syndrome (tonic pupils and tendon areflexia), and Ross syndrome (tonic pupils, tendon areflexia, and patchy hypohidrosis). In idiopathic cases, Harlequin syndrome is most commonly found in women and is typically triggered by emotions, exercise, heat, or spicy meals. It usually involves the face but can extend to the ipsilateral arm or trunk.

The phrase "secondary Harlequin syndrome" is used when Harlequin syndrome is caused by an underlying structural lesion. Causes reported in the literature include compression of the cervical sympathetic trunk by tumor, ${ }^{12}$ Pancoast tumor with spinal invasion, ${ }^{1}$ cervical lymphatic malformation, ${ }^{5}$ vascular compression due to an elongated inferior thyroid artery ${ }^{15}$ or dissection of the cervical ca- rotid artery, ${ }^{10}$ brachial plexopathies, ${ }^{1}$ or medullar infarction. ${ }^{7}$ As regards iatrogenic causes, Harlequin syndrome has been found after a range of anesthetic and surgical procedures, including internal jugular vein catheterization, ${ }^{4}$ thoracic epidural analgesia, ${ }^{2}$ resection of a cervical or mediastinal mass, ${ }^{5,13,14}$ or thoracic sympathectomy. ${ }^{1}$

Sympathetic innervation of the face and eyes comprises a 3-neuron chain and is represented in Fig. 3. The first neurons originate within the hypothalamus (central) and synapse in the lateral horn of the spinal cord at the thoracic level (T1-3) with the second or preganglionic neurons. From here, the preganglionic fibers ascend the sympathetic cervical trunk passing through the inferior (stellate) and middle (intermediate) cervical ganglia to synapse in the superior cervical ganglion. The third or postganglionic neuron exits this ganglion rostrally to follow the internal carotid artery to supply the eye and innervate the medial forehead and the nose, whereas fibers exiting this ganglion caudally pass along the external carotid artery to supply the rest of the face..$^{5}$ Most of the preganglionic vasomotor and sudomotor fibers dedicated to the face emerge at the level of T-2 and T-3, whereas most preganglionic oculosympathetic neurons originate at T-1. ${ }^{5,8,14}$ Preganglionic 
fibers innervating the upper extremity originate from T-4 and below. They synapse at the stellate ganglion, located more caudally, at the level of C-7.

Given these anatomical considerations, the location of the lesion along the sympathetic pathways can be determined according to the patient's presenting symptoms. In our case, concurrent Harlequin sign and Horner syndrome without involvement of the upper extremity and the trunk locates the lesion between the stellate ganglion and the superior cervical ganglion, which is consistent with the level of our surgical approach. Other lesion sites with the corresponding pattern of symptoms are shown in Fig. 3.

The occurrence of Harlequin sign and Horner syndrome together is extremely rare. Similar cases with the iatrogenic occurrence of both syndromes after surgery have been described after total thyroidectomy with neck dissection ${ }^{8}$ and following the removal of a large cervical lymphatic malformation in a child. ${ }^{5}$ In our case, the identified cause of sympathetic disruption was probably a too laterally situated dissection, which allowed the drain to be positioned against the sympathetic trunk and press on it while following the path of least resistance. The sympathetic cervical trunk lies in the prevertebral layer of the deep cervical fascia in front of the longus colli muscles, along the posteromedial aspect of the carotid sheath (Fig. 1). To avoid this complication, it is important to approach the spine not too laterally and to perform a meticulous subperiosteal lateral retraction of the longus colli muscles.

In most cases, Harlequin syndrome has a benign natural course and no active treatment is needed. In the iatrogenic cases described, the symptoms appeared temporarily and mostly resolved within a few hours. ${ }^{16}$ If no organic cause is identified, the patients have to be reassured and informed about the harmless character of this condition. Considering that Harlequin syndrome is secondary to a structural lesion (for example, tumor or arteries compressing the cervical sympathetic pathways), the lesion should be resected if feasible. ${ }^{1,12,15}$ Contralateral sympathectomy is a suggested treatment for people who experience severe social embarrassment due to their unilateral facial flushing. ${ }^{15}$

Despite its most often benign and reversible nature, this phenomenon can be quite impressive for both patient and surgeon. Therefore, knowledge of Harlequin syndrome alone or combined with Horner syndrome should be of particular interest for every specialist involved in cervical and thoracic surgery.

\section{Acknowledgments}

We thank Jérôme Kaufmann for contributing his time and expertise in illustrating Figs. 1 and 3.

\section{References}

1. Bremner F, Smith S: Pupillographic findings in 39 consecutive cases of harlequin syndrome. J Neuroophthalmol 28:171-177, 2008

2. Burlacu CL, Buggy DJ: Coexisting harlequin and Horner syndromes after high thoracic paravertebral anaesthesia. $\mathbf{B r}$ J Anaesth 95:822-824, 2005

3. Cauchoix J, Binet JP: Anterior surgical approaches to the spine. Ann R Coll Surg Engl 21:234-243, 1957

4. Coleman PJ, Goddard JM: Harlequin syndrome following internal jugular vein catheterization in an adult under general anesthetic. Anesthesiology 97:1041, 2002

5. Darvall JN, Morsi AW, Penington A: Coexisting harlequin and Horner syndromes after paediatric neck dissection: a case report and a review of the literature. J Plast Reconstr Aesthet Surg 61:1382-1384, 2008

6. Guilloton L, Demarquay G, Quesnel L, De Charry F, Drouet A, Zagnoli F: [Dysautonomic syndrome of the face with harlequin sign and syndrome: Three new cases and a review of the literature.] Rev Neurol (Paris) 169:884-891, 2013 (Fr)

7. Lance JW, Drummond PD, Gandevia SC, Morris JG: Harlequin syndrome: the sudden onset of unilateral flushing and sweating. J Neurol Neurosurg Psychiatry 51:635-642, 1988

8. Mohindra A, Herd MK, Roszkowski N, Downie IP: Concurrent Horner's and harlequin syndromes. Int J Oral Maxillofac Surg 44:710-712, 2015

9. Morris JG, Lee J, Lim CL: Facial sweating in Horner's syndrome. Brain 107:751-758, 1984

10. Sarikaya H, Georgiadis D, Baumgartner RW: Harlequin syndrome in spontaneous dissection of the cervical carotid artery. Neurology 71:1459, 2008

11. Southwick WO, Robinson RA: Surgical approaches to the vertebral bodies in the cervical and lumbar regions. J Bone Joint Surg Am 39-A:631-644, 1957

12. Tascilar N, Tekin NS, Erdem Z, Alpay A, Emre U: Unnoticed dysautonomic syndrome of the face: Harlequin syndrome. Auton Neurosci 137:1-9, 2007

13. Turco GR, Farber NE: Postoperative autonomic deficit: a case of harlequin syndrome. Anesthesiology 85:1197-1199, 1996

14. Van Slycke S, Stockman A, Dionigi G, Carette R, Gillardin JP, Brusselaers N, et al: Harlequin syndrome after thyroidectomy for compressive retrosternal goiter. Case report and review of the literature. Acta Chir Belg 114:212-214, 2014

15. Wasner G, Maag R, Ludwig J, Binder A, Schattschneider J, Stingele R, et al: Harlequin syndrome-one face of many etiologies. Nat Clin Pract Neurol 1:54-59, 2005

16. Willaert WI, Scheltinga MR, Steenhuisen SF, Hiel JA: Harlequin syndrome: two new cases and a management proposal. Acta Neurol Belg 109:214-220, 2009

\section{Disclosures}

The authors report no conflict of interest concerning the materials or methods used in this study or the findings specified in this paper.

\section{Author Contributions}

Conception and design: Fringeli. Acquisition of data: Fringeli. Analysis and interpretation of data: Fringeli, Humm, Ansorge. Drafting the article: Fringeli. Critically revising the article: Humm, Ansorge, Maestretti. Reviewed submitted version of manuscript: Fringeli, Humm, Ansorge. Approved the final version of the manuscript on behalf of all authors: Fringeli.

\section{Correspondence}

Yannick Fringeli, Chemin des Pensionnats 2, 1708 Fribourg, Switzerland. email: yannick.fringeli@hotmail.com. 